\title{
Whole grains protect against atherosclerotic cardiovascular disease
}

\author{
James W. Anderson \\ Metabolic Research Group, VA Medical Center and University of Kentucky, (111C) Cooper Drive Room B402, \\ Lexington, $K Y$ 40511, USA
}

\begin{abstract}
Atherosclerotic cardiovascular disease (ASCVD) is the most common cause of death in most Western countries. Nutrition factors contribute importantly to this high risk for ASCVD. Favourable alterations in diet can reduce six of the nine major risk factors for ASCVD, i.e. high serum LDL-cholesterol levels, high fasting serum triacylglycerol levels, low HDL-cholesterol levels, hypertension, diabetes and obesity. Wholegrain foods may be one the healthiest choices individuals can make to lower the risk for ASCVD. Epidemiological studies indicate that individuals with higher levels (in the highest quintile) of whole-grain intake have a $29 \%$ lower risk for ASCVD than individuals with lower levels (lowest quintile) of whole-grain intake. It is of interest that neither the highest levels of cereal fibre nor the highest levels of refined cereals provide appreciable protection against ASCVD. Generous intake of whole grains also provides protection from development of diabetes and obesity. Diets rich in wholegrain foods tend to decrease serum LDL-cholesterol and triacylglycerol levels as well as blood pressure while increasing serum HDL-cholesterol levels. Whole-grain intake may also favourably alter antioxidant status, serum homocysteine levels, vascular reactivity and the inflammatory state. Whole-grain components that appear to make major contributions to these protective effects are: dietary fibre; vitamins; minerals; antioxidants; phytosterols; other phytochemicals. Three servings of whole grains daily are recommended to provide these health benefits.
\end{abstract}

Atherosclerotic cardiovascular disease: Whole grains: Dietary fibre

Atherosclerotic cardiovascular diseases (ASCVD), including CHD, cerebrovascular disease and hypertensive heart disease, are the most common cause of death in Western countries and account for about $40 \%$ of all deaths (American Heart Association, 2000). Nutrition approaches to prevention are safer and more cost-effective than pharmacological approaches. Jenkins et al. (2000) recently summarized nutrition approaches to decreasing serum LDLcholesterol values, which is a major risk factor for CHD. These nutrition interventions, that have the potential to decrease serum LDL-cholesterol values by $35 \%$, include: low-saturated fat low-cholesterol diets; increased intake of soluble fibre; increased intake of soyabean protein; intake of plant sterols (Jenkins et al. 2000). Recent epidemiological evidence also indicates that higher intakes, when compared with lower intakes, of wholegrain foods are associated with lower risk for CHD (Anderson et al. 2000b).

The intake of wholegrain foods by adults in the USA and in Europe appears to be less than one serving per d, far below the recommended intake of three servings per $\mathrm{d}$ (Cleveland et al. 2000). The available clinical data suggest that adults would gain appreciable protection from CHD by consuming the recommended three servings of whole grains daily (Anderson et al. 2000b). Health claims for whole grains have been approved in the USA and UK. Wholegrain foods are rich sources of many nutrients and phytochemicals, including: complex carbohydrates; dietary fibre; resistant starch; oligosaccharides; minerals; n-3 fatty acids; vitamins; antioxidants; other phytochemicals (Slavin et al. 1997; Anderson et al. 2000b). The components that contribute to the health benefits have not been clearly identified and the mechanisms are poorly understood.

The present paper will specifically examine the strength of the association between whole grains and protection from ASCVD, contrast the effects of whole-grain intake $v$. refined-grain intake, and review proposed effects of whole grains on risk factors for CHD. 


\section{Atherosclerotic cardiovascular disease}

Strong evidence supporting the high-fibre food-CHD hypothesis first emerged clearly from the report of Morris et al. (1977). They observed that working men in the UK who had the highest intakes of cereal fibre had $80 \%$ lower rates of heart attacks than those with the lowest intake of cereal fibre. These observations have been confirmed and extended by a number of other investigators (Anderson et al. $2000 b)$.

Four studies have critically examined the association between whole-grain food intake and risk for CHD (Fraser et al. 1992; Jacobs et al. 1998, 1999; Liu et al. 1999). In addition, one study examined the association between whole-grain intake and ischaemic stroke (Liu et al. 2000). Previously, all the available controlled studies were tabulated to compare the effects of whole-grain intake with that of cereal fibre, total dietary fibre, and fruit and vegetable intakes on risk for CHD (Anderson et al. 2000b). The results of twenty-four controlled studies were tabulated and a meta-analysis was performed for the studies that provided adequate data for analysis. This earlier tabulation has been updated and the results are summarized in the present paper.

\section{Methods}

To appraise the literature, research reports that met the following criteria were identified: (1) inclusion of some dietary measure related to whole-grain, fibre or food intake; (2) reporting of outcome data related to CHD events; (3) presentation of an estimate of variance so that varianceadjusted calculations could be made (Anderson et al. $2000 b$ ). Thirty studies met the inclusion criteria and are included in the summary estimates provided in Table 1. Six of these studies did not provide sufficient data to calculate effect estimates. Four studies specifically reported on whole-grain intake and one study reported on wholewheat bread intake and was included in the whole-grain analysis (Fraser et al. 1992; Jacobs et al. 1998, 1999; Liu et al. 1999, 2000). Additional studies provided data on cereal fibre, total dietary fibre, and fruit and vegetable intakes (Anderson et al. 2000b). CHD events, CHD deaths or ischaemic strokes were assessed as the primary outcome measures.

Thirteen studies provided sufficient data and were appropriate for the meta-analysis calculations. Variance-adjusted event rates and $95 \%$ CI were calculated using fixed-effect model assumptions. All analyses were performed using

Table 1. Summary of studies reporting an association between type of food or fibre intake and risk for CHD (Anderson et al. 2000b)

\begin{tabular}{lccc}
\hline & \multicolumn{3}{c}{ No. of studies } \\
\cline { 2 - 4 } Food or fibre & Wotal & $\begin{array}{c}\text { With negative } \\
\text { association }\end{array}$ & $\begin{array}{c}\text { With significantly } \\
\text { negative association }\end{array}$ \\
\cline { 2 - 4 } Whole grains & 8 & 7 & 6 \\
Cereal & 8 & 7 & 5 \\
Total fibre & 17 & 16 & 14 \\
Fruit & 11 & 9 & 2 \\
Vegetables & 11 & 11 & 5 \\
\hline
\end{tabular}

SAS-PC version 6.12 (SAS Institute Inc., Cary, NC, USA), as previously described (Anderson et al. 2000b).

\section{Results}

Seven of eight reports assessing whole-grain intake and risk for ASCVD reported a negative association and six (75\%) noted a significant negative association (Table 1). Seven of eight reports assessing cereal-fibre intake and risk for CHD reported a negative association and five $(63 \%)$ noted a significant negative association. Sixteen of seventeen reports assessing total fibre intake and risk for CHD reported a negative association and fourteen (82\%) noted a significant negative association. Nine of eleven reports assessing fruit intake and risk for CHD reported a negative association but only two (18\%) noted a significant negative association. Finally, eleven of eleven reports assessing vegetable intake and risk for CHD reported a negative association and five (46\%) noted a significant negative association. Thus, in this semi-quantitative analysis total dietary fibre and whole-grain intakes show the strongest negative association with CHD events.

Results from the thirteen studies suitable for metaanalysis are presented in Table 2. These values were computed using values reported after secondary adjustment for covariates such as smoking, BMI, hypertension, supplement use and other factors, as detailed previously (Anderson et al. 2000b). Again, total dietary fibre and whole-grain intakes were associated with the greatest protection from CHD events. The risk ratio for whole grains comparing the lowest and highest groups of whole-grain intake was $0.71(95 \%$ CI $0.48,0.94)$ indicating that whole grains were associated with a significant reduction in risk approximating to $29 \%$. In sharp contrast, cereal fibre was not associated with a significant reduction in risk, having a risk ratio of $0.9(95 \% \mathrm{CI} 0.8,1.01)$. The risk reduction for CHD associated with total dietary fibre intake was 0.73 (95\% CI $0.73,0.83$ ); these values were virtually identical to those for whole-grain intake. Fruit intake was associated with a risk reduction of $0.77(95 \%$ CI $0.70,0.86)$ and vegetable intake was associated with a risk ratio of 0.86 (95\% CI 0.77, 0.96).

\section{Discussion}

This meta-analysis of multiple studies confirms and strengthens the observations of the individual studies suggesting that whole grains may have more protective action against CHD than other foods commonly eaten by

Table 2. Pooled analysis of data for food and fibre intake on adjusted relative risk for CHD (Data updated from Anderson et al. 2000b)

\begin{tabular}{lcccc}
\hline & & \multicolumn{2}{c}{$95 \% \mathrm{Cl}$} \\
\cline { 4 - 5 } Food or fibre source & No. of studies & Risk ratio & Lower & Upper \\
\hline Whole grains & 5 & 0.71 & 0.48 & 0.94 \\
Cereal fibre & 4 & 0.9 & 0.8 & 1.01 \\
Total fibre & 6 & 0.73 & 0.65 & 0.83 \\
Fruit & 7 & 0.77 & 0.7 & 0.86 \\
Vegetables & 8 & 0.86 & 0.77 & 0.96 \\
\hline
\end{tabular}


North Americans and Europeans. Whole-grain intake appears to be slightly more protective than fruit or vegetable intakes. The protection associated with whole-grain intake is virtually identical to that provided by total dietary fibre. It is of interest that this analysis indicates that cereal fibres are not associated with a substantial protective effect. This finding appears to be questionable until it is noted that the endosperm of most grains is rich in hemicelluloses but has minimal levels of phytochemicals (MacDougall \& Selvendran, 2001). Most antioxidants, phytosterols and other phytochemicals are concentrated in the bran or germ of most cereals (Slavin et al. 1997; Miller et al. 2000).

\section{Whole-grain $v$. refined-grain intake and atherosclerotic cardiovascular disease}

Neither cereal fibre intake nor refined-grain intake appears to provide the protection from ASCVD that is reported for whole-grain intake. Our meta-analysis indicated that cereal fibre had a negative association with CHD risk which did not reach statistical significance (Anderson et al. 2000b). Reports from both the Iowa Women's Health Study and the Nurses' Health Study indicate that whole-grain intake has a significant negative association with $\mathrm{CHD}$ or ischaemic stroke whereas refined-grain intake does not appear related (Jacobs et al. 1999; Liu et al. 2000). Jacobs et al. (1999) noted that women with the highest quintile for whole-grain intake had a reduction in CHD by $14 \%(P=0.005)$ compared with the lowest quintile. However, women with the highest level of refined-grain intake had a $9 \%$ increase in CHD risk $(P=0 \cdot 7)$ compared with women with the lowest level. Liu et al. (2000) reported that women with the highest level of whole-grain intake had a $31 \%$ lower risk $(P=0 \cdot 08)$ for ischaemic stroke than women with the lowest level of intake. However, women with the highest level of refinedgrain intake had ischaemic strokes at the same rate as women with the lowest intake.

The differences in CHD risk associated with different parts of the cereal grain may relate to differences in the composition and constituents of the dietary fibre. Refined grain products contain only the endosperm (starch and hemicelluloses) while wholegrain products include the endosperm, bran layer and germ. The bran layer and germ are rich in dietary fibre, phytochemicals and other components that may provide cardiovascular protection (MacDougall \& Selvendran, 2001).

\section{Effects on risk factors}

Some of the major risk factors for CHD that are reversible include: increased LDL-cholesterol levels; high fasting serum triacylglycerols; low HDL-cholesterol values; hypertension; diabetes; obesity; lack of exercise; poor stress management; cigarette smoking (Anderson et al. 1990; Kannel, 1996; Krauss et al. 2000). The first six of these major risk factors may be favourably altered by dietary intervention. The following risk factors are emerging as important considerations for their role in CHD: low antioxidant vitamin status (Jha et al. 1995); hyperhomocysteinaemia (Welch \& Loscalzo, 1998); evidence of an inflammatory state (Ross, 1999). Whole grains have the potential to favourably alter the following risk factors: elevated serum LDL-cholesterol values; hypertriacylglycerolaemia; decreased serum HDL-cholesterol values; hypertension; diabetes; obesity; insulin resistance; suboptimal antioxidant status; hyperhomocysteinaemia; altered vascular reactivity; the inflammatory state. These areas will be reviewed to illustrate and discuss the potential benefits of whole-grain intake.

\section{Abnormalities of LDL-cholesterol}

Changes in serum levels, particle size and oxidation of LDL appear to play a central role in the pathogenesis of atherosclerosis. Abnormalities of this particle may be the single greatest risk factor for atherosclerotic disease in Western populations (Navab et al. 1996). Wholegrain oat products are particularly effective in decreasing serum LDL-cholesterol concentrations (Anderson \& Gustafson, 1988; Ripsin et al. 1992). Wholegrain barley products also effectively decrease serum LDL-cholesterol values (McIntosh et al. 1991). While less potent, wheat products with moderate amounts of soluble fibre have LDL-cholesterol-lowering properties (Anderson et al. 1991a). Whole grains appear to exert some of, but not all, their protective effects to reductions in serum LDL-cholesterol values (Truswell, 2002).

\section{Hypertriacylglycerolaemia}

Elevations in serum triacylglycerols values reflect a substantial increase in risk for CHD, but whether the triacylglycerol-rich particles carry the risk or simply serve as markers for a constellation of other risk factors such as insulin resistance is unclear (Ginsberg, 1997). Elevations in fasting triacylglycerols may reflect a derangement of lipoprotein metabolism as well as lipoprotein particle size and composition that increase risk through poorly understood mechanisms (Rubins et al. 1999; Anderson, 2000). Since Zilversmit (1979) advanced the hypothesis relating postprandial lipaemia to atherosclerosis, this area has been extensively investigated. Most of the epidemiological data indicate a positive association between fasting serum triacylglycerols and CHD risk (Ginsberg, 1997). The effects of diet on fasting serum triacylglycerols are also controversial. While replacing dietary fat with carbohydrate usually increases fasting serum triacylglycerol values (Park \& Hellerstein, 2000), an increase in dietary carbohydrate and fibre at the expense of dietary fat does not affect triacylglycerol levels (Anderson, 2000). Furthermore, decreasing dietary fat intake and increasing dietary carbohydrate intake decreases postprandial hypertriacylglycerolaemia (Anderson et al. 1980). A recent clinical trial confirmed the effects of dietary fibre in decreasing fasting serum triacylglycerol values (Chandalia et al. 2000). Thus, several careful studies indicate that increased intake of whole grains is likely to decrease fasting and postprandial serum triacylglycerol values (Anderson et al. 1980, 1991b; Anderson, 2000; Chandalia et al. 2000).

\section{Low HDL-cholesterol}

Alterations in HDL levels or function may be the second most important lipoprotein disturbance linked to CHD 
(Gowri et al. 1999; Rubins et al. 1999). Dietary fibres usually have a neutral effect on serum HDL-cholesterol values (Olson et al. 1997; Brown et al. 1999; Anderson et al. 2000a). Psyllium intake may increase apolipoprotein A-I, a protective component of HDL (Anderson et al. $2000 a$ ). Intake of soyabean protein tends to increase serum HDL-cholesterol values slightly but not significantly (Anderson et al. 1995). While not carefully examined, it seems probable that increased intake of whole grains would increase HDL concentrations and favourably affect function (Fung et al. 2001).

\section{Hypertension}

The three most important risk factors for CHD appear to be hypercholesterolaemia, cigarette smoking and hypertension; these factors are sometimes referred to as the 'Big Three' (Anderson et al. 1990; Kannel, 1996). Early clinical research with dietary fibre showed a reduction in blood pressure when diabetic individuals were placed on highfibre high-carbohydrate diets (Anderson, 1983). Subsequent studies reported that high fibre intakes reduced blood pressure (Anderson, 1995). Limitations of these studies relate to the fact that high-fibre foods are higher in complex carbohydrate and fibre and lower in fat than control foods. Fibre supplements may not mimic the effects of whole foods in these clinical studies. A careful meta-analysis of the evidence indicates that increasing dietary fibre intake with body-weight maintenance is associated with a small, but statistically significant, reduction in blood pressure (He \& Whelton, 1999). Additional epidemiological evidence also supports the protective role for fibre with respect to hypertension (Ascherio et al. 1992).

A landmark clinical trial, the Dietary Approaches to Stop Hypertension, encouraged a healthy diet including vegetables, fruits and whole grains (Appel et al. 1997). While rich in $\mathrm{K}, \mathrm{Mg}$ and $\mathrm{Ca}$, this diet was also generous in dietary fibre. For non-hypertensive individuals this diet decreased systolic and diastolic blood pressure by 3.5 and $2.1 \mathrm{mmHg}$ respectively. Reductions in blood pressure in hypertensive individuals were substantially greater. This important study, the findings of which were subsequently confirmed, emphasizes the benefits of dietary interventions in the first-line treatment of hypertension (Sacks et al. 2001). It seems probable that the increased intake of whole grains would slow the development of hypertension and lower blood pressure in hypertensive individuals.

\section{Diabetes}

Diabetes was recently upgraded to a major risk factor for CHD joining the 'Big Three' (Krauss et al. 2000). Dietary fibre and whole-grain intake protect from development of diabetes and, furthermore, improve glycaemic management in diabetic individuals. As reviewed by Anderson \& Akanji (1991), the initial clinical research with dietary fibre focused on its effects for individuals with diabetes. Subsequently, the Anderson team (Anderson \& Akanji, 1991) utilized diets rich in high-fibre foods and whole grains to show dramatic improvement in glycaemic control with marked decreases in insulin or oral medication requirements for diabetic individuals. Concurrently, Vinik \& Jenkins (1988) utilized fibre supplements in diabetic individuals. Vinik and Jenkins (1988) showed that taking fibre supplements with meals markedly reduced postprandial hyperglycaemia. The observations led to the 'glycaemic index' concept. The glycaemic index, of course, is affected by fibre and by many other characteristics of the meal (Jenkins et al. 1981). In combination these studies established the important role of dietary fibre in the management of diabetes (Anderson, 1999). Recent studies confirm the benefits of dietary fibre for individuals with diabetes (Anderson et al. 1999a; Chandalia et al. 2000).

Recent observational studies indicate that a high fibre intake is associated with a marked reduction in the prevalence of diabetes (Salmeron et al. 1997a,b; Meyer et al. 2000). More specifically, Meyer et al. (2000) reported that the highest quintile of whole-grain intake was associated with a significant reduction $(21 \%, P=0.0089)$ in risk for developing diabetes. These data are supported by clinical studies indicating that whole-grain intake increases insulin sensitivity (Pereira et al. 2002) and has a favourable impact on gut-hormone and insulin responses after meals (Juntunen et al. 2000). It seems probable that increased intake of whole grains would decrease the prevalence of diabetes and improve blood glucose management in diabetic individuals.

\section{Obesity}

Obesity has not been given the attention it deserves as an independent risk factor for CHD (Manson et al. 1995; Anderson \& Konz, 2001). For approximately 30 years epidemiological data, observational studies, human experimental research and clinical trials support a role for dietary fibre in the development and management of obesity (Anderson \& Bryant, 1986). For example, a recent observational study reported that individuals with higher fibre intakes had markedly lower rates of obesity than individuals with lower fibre intakes (Ludwig et al. 1999). Many clinical trials suggest a role for dietary fibre in the management of obesity, but the data are not conclusive. The use of blinding in clinical trials involving high-fibre foods has not been possible and placebo effects may have contributed to favourable outcomes. Since the early study of Mickelsen et al. (1979) demonstrating the weight-reducing benefits of high-fibre bread, many clinical studies have reported weight-loss benefits from increasing fibre intake (Anderson \& Sieling, 1980; Duncan et al. 1983; Anderson, 1985; Russ \& Atkinson, 1985). Thus, the available data, while not conclusive, strongly indicate that dietary fibre may offer sustantial benefits in the clinical management of obesity. It seems probable that increased intake of whole grains would decrease the risk for developing obesity, have a beneficial role in weight management and, thereby, decrease risk for ASCVD.

\section{Insulin resistance}

The insulin resistance syndrome is emerging as a major contributor to risk for CHD. Insulin resistance is characterized 
by hyperinsulinaemia, hypertriacylglycerolaemia and low HDL-cholesterol concentrations, and affects about 47 million adults in the USA (Ford et al. 2002). Commonly-associated features are visceral adiposity, hypertension and glucose intolerance or diabetes (Reaven, 1988; Anderson \& Hanna, 1999). Hyperinsulinaemia, itself, may be an independent risk factor for $\mathrm{CHD}$, although many researchers consider it a marker for the insulin resistance syndrome (Despres et al. 1996). As reviewed elsewhere, high fibre intakes decrease hyperinsulinaemia, decrease insulin resistance and combat this hazardous syndrome (Anderson \& Hanna, 1999). Our previous studies indicate that high carbohydrate intakes together with high fibre intakes decrease insulin requirements in diabetic individuals (Anderson et al. 1991b) and increase sensitivity to insulin for non-diabetic individuals (Fukagawa et al. 1990). Pereira et al. (2002) recently reported that short-term increases in the intake of whole grains increased insulin sensitivity of overweight hyperinsulinaemic adults. The mechanism responsible for this improvement in insulin sensitivity is unclear. Thus, it seems probable that increased whole-grain intake would improve insulin sensitivity and decrease risk for CHD for hyperinsulinaemic individuals, but more research is required in this area.

\section{Sub-optimal antioxidant status}

Low intakes of antioxidant vitamins, especially vitamin E, appear to be associated with high risk for CHD (Gey et al. 1993; Rimm et al. 1993; Stampfer et al. 1993; Regnstrom et al. 1996). These observations are consistent with the hypothesis that oxidation of LDL has a major role in the pathogenesis of atherosclerosis (Navab et al. 1996; Anderson et al. 1999b). However, intervention trials utilizing antioxidant vitamin supplements are not conclusive (Jha et al. 1995). In fact, recent studies suggest that vitamin E may diminish the protective effects of hypocholesterolaemic 'statins' drugs when the two supplements are administered concurrently (Brown et al. 2001). Nevertheless, whole grains are excellent sources of antioxidant vitamins and phytochemicals and may protect from CHD through these substances (Miller et al. 2000).

\section{Hyperhomocysteinaemia}

Homocysteine, an S-containing amino acid, has a variety of toxic effects on the vascular endothelium and also increases risk for thrombosis (Welch \& Loscalzo, 1998). McCulley (1969) noted that hyperhomocysteinaemia was associated with severe atherosclerotic vascular disease. Subsequent epidemiological studies have reported a strong association between serum homocysteine levels and CHD and cerebral vascular disease (Kang et al. 1992; Boushey et al. 1995; Selhub et al. 1995; Stampfer \& Malinow, 1995). Suboptimal intakes of folic acid, pyridoxine and cobalamin are associated with higher serum homocysteine levels, and supplementation with these vitamins decreases serum levels (Welch \& Loscalzo, 1998). Intake of wholegrain products, especially those fortified with water-soluble vitamins (Boushey et al. 1995), would also act to reduce serum homocysteine levels and decrease risk for ASCVD (Boushey et al. 1995; Jacques et al. 1999).

\section{Altered vascular reactivity}

While favourable lipid profiles protect premenopausal women from $\mathrm{CHD}$, new evidence suggests that effects of oestrogen on vascular reactivity may have an even greater protective effect (Reis et al. 1994; Subbiah, 1998; Mendelsohn \& Karas, 1999). Oestrogens bind to specific intracellular receptors and protect blood vessels from injury and atherosclerosis. These hormones promote appropriate vasodilatation of coronary arteries when increased blood supply is required (Mendelsohn \& Karas, 1999). Soyabean isoflavones, potent agonists of $\beta$-oestrogen receptors in blood vessels, appear to act in a similar manner to mammalian oestrogens (Honore et al. 1997; Williams \& Clarkson, 1998). Preliminary studies suggest that soyabean isoflavones have similar effects on peripheral blood vessels in human subjects (Nestel et al. 1997). Whole grains also provide phyto-oestrogens that are likely to have similar protective effects on blood vessels (Slavin et al. 1997). Thus, it seems probable that phyto-oestrogens from whole grains have a protective effect on vascular reactivity and reduce risk for vascular events related to arterial spasm.

\section{Increased inflammatory state}

Recent research reinforces the role of inflammation in the pathogenesis of atherosclerosis (Ross, 1999). Some of the evidence linking inflammation to atherosclerosis is summarized as follows: histological evidence of inflammation in atherosclerotic plaques; increased circulating levels of thromboxanes and leukotrienes; activated circulating leukocytes; increased serum concentrations of C-reactive protein (Albert et al. 2002). Soyabean isoflavones, more extensively studied than similar phyto-oestrogens (lignans) from whole grains (Slavin et al. 1997), have a number of anti-inflammatory actions. Isoflavones inhibit adhesion molecule expression, alter arachidonic acid metabolism, inhibit oxygen radical generation and inhibit chemotactic factor production (Sadowska-Krowicka et al. 1998; Regal et al. 2000). These isoflavones demonstrate anti-inflammatory potential in a number of animal models such as chronic ileitis, inflammation-induced corneal neovascularization and ischaemic reperfusion injury (Regal et al. 2000). Emerging evidence suggests that soyabean isoflavones may inhibit some of the cellular processes contributing to the atherosclerotic lesion (Raines \& Ross, 1995). The potential role of lignans in whole grains in reducing inflammation as it relates to protection from CHD requires further study.

\section{Other factors}

Minor components of whole grains, including $n$ - 3 fatty acids and certain minerals (e.g. $\mathrm{Zn}, \mathrm{Cr}$ and $\mathrm{Mg}$ ), may also contribute to their protective effect for CHD (Slavin et al. 1997). Soyabean isoflavones exert anti-thrombotic and antiplatelet aggregating effects (Wilcox \& Blumenthal, 1995). Since thrombus formation precedes most myocardial infarction, decreasing platelet aggregation and thrombo- 
genesis could protect from these events. Whole-grain phytochemicals are likely to have similar anti-platelet aggregating and anti-thrombotic effects (Slavin et al. 1997).

\section{Conclusions}

Whole grains are among the healthiest food choices that individuals make. These foods are rich in fibre and phytochemicals and have a wide variety of health benefits. Recently, health claims suggesting that whole-grain intake may reduce risk for CHD were approved in the USA and the UK. The US Department of Agriculture recommended that all individuals consume three servings of whole grains daily. Whole-grain intake appears to protect from development of CHD and diabetes. The emerging science regarding health benefits and mechanisms strongly supports these nutrition guidelines.

\section{References}

Albert CM, Rifai N, Stampfer M \& Ridker P (2002) Prospective study of C-reactive protein, homocysteine, and plasma lipid levels as predictors of sudden cardiac death. Circulation 105, 2595-2599.

American Heart Association (2000) 2000 Heart and Stroke Statistical Update, pp. 1-32. Dallas, TX: American Heart Association.

Anderson J (1983) Plant fiber and blood pressure. Annals of Internal Medicine 98, 842-846.

Anderson J (1985) High-fiber diets for obese diabetic men on insulin therapy: short-term and long-term effects. In Dietary Fiber and Obesity, pp. 49-68 [GV Vahouny, editor]. New York: Alan R. Liss Inc.

Anderson J (1995) Dietary fibre, complex carbohydrate and coronary artery disease. Canadian Journal of Cardiology 11, $55 \mathrm{G}-62 \mathrm{G}$.

Anderson J (1999) Nutritional management of diabetes mellitus. In Modern Nutrition in Health and Disease, 9th ed., pp. 1365-1395 [ME Shils, JA Olson and M Shike, editors]. Baltimore, MD: Williams and Wilkins.

Anderson J (2000) Dietary fiber prevents carbohydrate-induced hypertriglyceridemia. Current Atherosclerosis Reports 2 , 536-541.

Anderson J \& Akanji A (1991) Dietary fiber - an overview. Diabetes Care 14, 1126-1131.

Anderson J, Allgood L, Lawrence A, Altringer L, Jerdack G \& Hengehold D (2000a) Cholesterol-lowering effects of psyllium intake adjunctive to diet therapy in men and women with hypercholesterolemia: meta-analysis of 8 controlled trials. American Journal of Clinical Nutrition 71, 472-479.

Anderson J, Allgood L, Turner C, Oelgten P \& Daggy B (1999a) Effects of psyllium on glucose and serum lipid responses in men with type 2 diabetes and hypercholesterolemia. American Journal of Clinical Nutrition 70, 466-473.

Anderson J \& Bryant CA (1986) Dietary fiber: diabetes and obesity. American Journal of Gastroenterology 81, 898-906.

Anderson J, Chen W \& Sieling B (1980) Hypolipidemic effects of high-carbohydrate, high-fiber diets. Metabolism 29, 551-558.

Anderson J, Deakins DA, Floore TL, Smith BM \& Whitis SE (1990) Dietary fiber and coronary heart disease. Critical Reviews in Food Science and Nutrition 29, 95-147.

Anderson J, Gowri M, Turner J, Nichols L, Diwadkar V, Chow C \& Oelgten P (1999b) Antioxidant supplementation effects on low-density lipoprotein oxidation for individuals with noninsulin dependent diabetes mellitus. Journal of the American College of Nutrition 18, 451-461.

Anderson J \& Gustafson N (1988) Hypocholesterolemic effects of oat and bean products. American Journal of Clinical Nutrition 48, 749-753.

Anderson J \& Hanna TJ (1999) Impact of nondigestible carbohydrates on serum lipoproteins and risk for cardiovascular disease. Journal of Nutrition 129, 1457S-1466S.

Anderson J, Hanna TJ, Peng X \& Kryscio R (2000b) Whole grain foods and heart disease risk. Journal of the American College of Nutrition 19, 291S-299S.

Anderson J, Johnstone B \& Cook-Newell M (1995) Meta-analysis of effects of soy protein intake on serum lipids in humans. New England Journal of Medicine 333, 276-282.

Anderson J \& Konz EC (2001) Obesity and disease management: Effects of weight loss on co-morbid conditions. Obesity Research 9, 326S-334S.

Anderson J, Riddell-Lawrence S, Floore T, Dillon D \& Oelgten P (1991a) Bakery products lower serum cholesterol concentrations in hypercholesterolemic men. American Journal of Clinical Nutrition 54, 836-840.

Anderson J \& Sieling B (1980) High fiber diets for obese diabetic patients. Obesity/Bariatric Medicine 9, 109-113.

Anderson J, Zeigler J, Floore T, Dillon D, Wood C, Oeltgen P \& Whitley R (1991b) Metabolic effects of high-carbohydrate, highfiber diets for insulin-dependent diabetic individuals. American Journal of Clinical Nutrition 54, 936-943.

Appel L, Moore T, Obarzanek E, Vollmer W, Svetkey L, Sacks F, Bray G, Vogt T, Cutler J, Windhauser M, Lin P \& Karanja N (1997) A clinical trial of the effects of dietary patterns on blood pressure. DASH Collaborative Research Group. New England Journal of Medicine 336, 1117-1124.

Ascherio A, Rimm EB, Giovannucci EL, Colditz GA, Rosner B, Willett WC, Sacks F \& Stampfer MJ (1992) A prospective study of nutritional factors and hypertension among US men. Circulation 86, 1475-1484.

Boushey CJ, Beresford SA, Omenn GS \& Motulsky AG (1995) A quantitative assessment of plasma homocysteine as a risk factor for vascular disease. Journal of the American Medical Association 274, 1049-1057.

Brown B, Zhao X-Q, Chait A, Fisher L, Cheung M, Morse J, Dowdy A, Marino E, Bolson E, Alaupoviv P, Frohlich J \& Albers J (2001) Simvastatin and niacin, antioxidant vitamins, another combination for the prevention of coronary disease. New England Journal of Medicine 345, 1583-1592.

Brown L, Rosner B, Willett W \& Sacks F (1999) Cholesterollowering effects of dietary fiber: a meta-analysis. American Journal of Clinical Nutrition 69, 30-42.

Chandalia M, Garg A, Lutjohann D, von Bergmann K, Grundy S \& Brinkley L (2000) Beneficial effects of high dietary fiber intake in patients with Type 2 diabetes mellitus. New England Journal of Medicine 342, 1392-1398.

Cleveland LE, Moshfegh AJ, Albertson AM \& Goldman JD (2000) Dietary intake of whole grains. Journal of the American College of Nutrition 19, 331S-338S.

Despres J-P, Lamarche B \& Mauriege P (1996) Hyperinsulinemia as an independent risk factor for ischemic heart disease. New England Journal of Medicine 334, 952-957.

Duncan KH, Bacon JA \& Weinsier RL (1983) The effects of high and low energy density diets on satiety, energy intake, and eating time of obese and nonobese subjects. American Journal of Clinical Nutrition 37, 763-767.

Ford E, Giles W \& Dietz W (2002) Prevalence of the metabolic syndrome among US adults. Journal of the American Medical Association 287, 356-359. 
Fraser GE, Sabate J, Beeson WL \& Strahan TM (1992) A possible protective effect of nut consumption on risk of coronary heart disease. Archives of Internal Medicine 152, 1416-1424.

Fukagawa NK, Anderson J, Young VR \& Minaker KL (1990) High-carbohydrate, high-fiber diets increase peripheral insulin sensitivity in healthy young and old adults. American Journal of Clinical Nutrition 52, 524-528.

Fung T, Rimm E, Spiegelman D, Rifai N, Tofler G, Willett W \& Hu F (2001) Association between dietary patterns and plasma biomarkers of obesity and cardiovascular disease risk. American Journal of Clinical Nutrition 73, 61-67.

Gey K, Moser U, Jordan P, Stahelm H, Eichholzer M \& Ludin E (1993) Increased risk of cardiovascular disease at suboptimal plasma concentrations of essential antioxidants: an epidemiologic update with special attention to carotene and vitamin C. American Journal of Clinical Nutrition 57, 787S-797S.

Ginsberg H (1997) Is hypertriglyceridemia a risk factor for atherosclerotic cardiovascular disease: a simple question with a complicated answer. Annals of Internal Medicine 126, 912-914.

Gowri MS, Van der Westhuyzen DR, Bridges SR \& Anderson J (1999) Decreased protection by HDL from poorly controlled type 2 diabetic subjects against LDL oxidation may be due to the abnormal composition of HDL. Arteriosclerosis, Thrombosis and Vascular Biology 9, 2226-2233.

He J \& Whelton PK (1999) Effect of dietary fiber and protein intake on blood pressure: a review of epidemiologic evidence. Clinical and Experimental Hypertension 21, 785-796.

Honore EK, Williams JK, Anthony MS \& Clarkson TB (1997) Soy isoflavones enhance coronary vascular reactivity in atherosclerotic female macaques. Fertility and Sterility 67, 148-154.

Jacobs D, Meyer K, Kushi L \& Folsom A (1998) Whole-grain intake may reduce the risk of ischemic heart disease death in postmenopausal women: the Iowa Women's Health Study. American Journal of Clinical Nutrition 68, 248-257.

Jacobs D, Meyer K, Kushi L \& Folsom A (1999) Is whole grain intake associated with reduced total and cause-specific death rates in older women? The Iowa Women's Health Study. American Journal of Public Health 89, 322-329.

Jacques H, Gascon A, Arul J, Boudreau A, Lavigne C \& Bergeron J (1999) Modified milk fat reduces plasma triacylglycerol concentrations in normolipidemic men compared with regular milk fat and nonhydrogenated margarine. American Journal of Clinical Nutrition 70, 983-991.

Jenkins D, Kendall C \& Vuksan V (2000) Viscous fibers, health claims, and strategies to reduce cardiovascular disease. American Journal of Clinical Nutrition 71, 401-402.

Jenkins D, Wolever T, Taylor R, Barker H, Fielden H, Baldwin J, Bowling A, Newman H, Jenkins A \& Goff D (1981) Glycemic index of foods: a physiologic basis for carbohydrate exchange. American Journal of Clinical Nutrition 34, 362-366.

Jha P, Flather M, Lonn E, Farkouh M \& Yusuf S (1995) The antioxidant vitamins and cardiovascular disease. Annals of Internal Medicine 123, 860-872.

Juntunen KS, Mazur WM, Liukkonen KH, Uehara M, Poutanen KS, Adlercreutz HC \& Mykkanen HM (2000) Consumption of wholemeal rye bread increases serum concentrations and urinary excretion of enterolactone compared with consumption of white wheat bread in healthy Finnish men and women. British Journal of Nutrition 84, 839-846.

Kang S-S, Wong PW \& Malinow M (1992) Hyperhomocysti(e)nemia as a risk factor for occlusive vascular disease. Annual Review of Nutrition 12, 279-298.

Kannel W (1996) Blood pressure as a cardiovascular risk factor. Journal of the American Medical Association 275, 1571-1576.

Krauss R, Eckel R, Howard B, Appel L, Daniels S, Deckelbaum R, Erdman J, Kris-Etherton P, Goldberg I, Kotchen T, Lichtenstein
A, Mitch W, Mullis R, Robinson K, Wylie-Rosett J, St Jeor S, Suttie J, Tribble D \& Bazzarre T (2000) AHA Guidelines Revision 2000: A statement for healthcare professionals from the Nutrition Committee of the American Heart Association. Circulation 102, 2296-2311.

Liu S, Manson JE, Stampfer MJ, Rexrode KM, Hu FB, Rimm EB \& Willett WC (2000) Whole grain consumption and risk of ischemic stroke in women: A prospective study. Journal of the American Medical Association 284, 1534-1540.

Liu S, Stampfer M, Hu F, Giovannucci E, Rimm E, Manson J, Hennekens C \& Willett W (1999) Whole-grain consumption and risk of coronary heart disease: results from the Nurses' Health Study. American Journal of Clinical Nutrition 70, 412-419.

Ludwig D, Pereira M, Kroenke C, Hilner J, Van Horn L, Slattery M \& Jacobs D Jr (1999) Dietary fiber, weight gain, and cardiovascular disease risk factors in young adults. Journal of the American Medical Association 282, 1539-1546.

McCully K (1969) Vascular pathology of homocysteinemia: implications for the pathogenesis of arteriosclerosis. American Journal of Pathology 56, 111-128.

MacDougall AJ \& Selvendran RR (2001) Chemistry, architecture, and composition of dietary fiber from plant cell walls. In Handbook of Dietary Fiber, pp. 281-319 [SS Cho and ML Dreher, editors]. New York: Marcel Dekker, Inc.

McIntosh G, Whyte J, McArthur R \& Nestel P (1991) Barley and wheat foods: influence on plasma cholesterol concentrations in hypercholesterolemic men. American Journal of Clinical Nutrition 53, 1205-1209.

Manson J, Willett W, Stampfer M, Colditz G, Hunter D, Hankinson S, Hennekens C \& Speizer F (1995) Body weight and mortality among women. New England Journal of Medicine 333, 677-685.

Mendelsohn M \& Karas R (1999) The protective effects of estrogens on the cardiovascular system. New England Journal of Medicine 340, 1801-1811.

Meyer K, Kushi L, Jacobs D, Slavin J, Sellers T \& Folsom A (2000) Carbohydrates, dietary fiber, and incidence of type 2 diabetes in older women. American Journal of Clinical Nutrition 71, 921-930.

Mickelsen O, Makdani DD, Cotton RH, Titcomb ST, Colmey JC \& Gatty R (1979) Effects of a high fiber bread diet on weight loss in college-age males. American Journal of Clinical Nutrition 32, 1703-1709.

Miller H, Rigelhop F, Marquart L, Prakash A \& Kanter M (2000) Whole-grain products and antioxidants. Cereal Foods World 45, $59-63$.

Morris J, Marr J \& Clayton D (1977) Diet and heart: a postscript. British Medical Journal 2, 1307-1314.

Navab M, Berliner J, Watson A, Hama S, Territo M, Lusis A, Shih D, Van Lenten B, Frank J, Demer L, Edwards P \& Fogelman A (1996) The Yin and Yang of oxidation in the development of the fatty streak. Arteriosclerosis, Thrombosis and Vascular Biology 16, 831-842.

Nestel PJ, Yamashita T, Sasahara T, Pomeroy S, Dart A, Komesaroff P, Own A \& Abbey M (1997) Soy isoflavones improve systemic arterial compliance but not plasma lipids in menopausal and perimenopausal women. Arteriosclerosis, Thrombosis and Vascular Biology 17, 3392-3398.

Olson B, Anderson S, Becker M, Anderson J, Hunninghake D, Jenkins D, LaRosa J, Rippe J, Roberts D, Stoy D, Summerbell C, Truswell A, Wolever T, Morris D \& Fulgoni V (1997) Psylliumenriched cereals lower blood total cholesterol and LDL cholesterol, but not HDL cholesterol in hypercholesterolemic adults: results of a meta-analysis. Journal of Nutrition 127, 1973-1980.

Park E \& Hellerstein M (2000) Carbohydrate-induced hypertriacylglycerolemia: historical perspective and review of biological mechanisms. American Journal of Clinical Nutrition 71, 412-433. 
Pereira M, Jacobs D Jr, Pins J, Raatz SK, Gross MD, Slavin J \& Seaquist ER (2002) Effect of whole grains on insulin sensitivity in overweight hyperinsulinemic adults. American Journal of Clinical Nutrition 75, 848-855.

Raines EW \& Ross R (1995) Biology of atherosclerotic plaque formation: possible role of growth factors in lesion development and the potential impact of soy. Journal of Nutrition 125, 624S-630S.

Reaven G (1988) Role of insulin resistance in human disease. Diabetes 37, 1595-1607.

Regal JF, Fraser DG, Weeks CE \& Greenberg NA (2000) Dietary phytoestrogens have anti-inflammatory activity in a guinea pig model of asthma. Experimental Biology and Medicine 223, 372-378.

Regnstrom J, Nilsson J, Strom K, Bavenholm P, Tornvall P \& Hamsten A (1996) Inverse relationship between concentration of vitamin $\mathrm{E}$ and severity of coronary artery disease. American Journal of Clinical Nutrition 63, 377-385.

Reis S, Gloth S, Blumenthal R, Resar J, Zacur H, Gerstenblith G \& Brinker J (1994) Ethinyl estradiole acutely attenuates abnormal coronary vasomotor responses to acetyl choline in postmenopausal women. Circulation 89, 52-60.

Rimm E, Stampfer M, Ascherio A, Giovannucci E, Colditz G \& Willett W (1993) Vitamin E consumption and the risk of coronary heart disease in man. New England Journal of Medicine 328, 1450-1456.

Ripsin CM, Keenan JM, Jacobs DR, Elmer PJ, Welch RR, Van Horn L, Liu K, Turnbull WH, Thye FW, Kestin M, Hegsted M, Davidson DM, Davidson MH, Dugan LD, Demark-Wahnefried W \& Beling S (1992) Oat products and lipid lowering. Journal of the American Medical Association 267, 3317-3325.

Ross R (1999) Atherosclerosis is an inflammatory disease. American Heart Journal 138, S419-S420.

Rubins H, Robins S, Collins D, Fye C, Anderson J, Elam M, Faas F, Linares E, Schaefer E, Schectman G, Wilk T \& Wittes J (1999) Gemfibrozil for the secondary prevention of coronary heart disease in men with low levels of high-density lipoprotein cholesterol. New England Journal of Medicine 341, 410-418.

Russ C \& Atkinson R (1985) A comprehensive outpatient weight reduction program: dietary patterns, psychological considerations, and treatment principles. Nutrition Reports International 32, 193-198.

Sacks FM, Svetkey LP, Vollmer WM, Appel LJ, Bray GA, Harsha D, Obarzanek E, Conlin PR, Miller ER, Simons-Morton D, Karanja N \& Pao-Hwa L (2001) Effects on blood pressure of reduced dietary sodium and the dietary approaches to stop hypertension (DASH) diet. New England Journal of Medicine 344, 3-10.

Sadowska-Krowicka H, Mannick EE, Oliver PD, Sandoval M, Zhang XJ, Eloby-Childess S, Clark DA \& Miller MJS (1998) Genistein and gut inflammation: role of nitric oxide. Experimental Biology and Medicine 217, 351-357.

Salmeron J, Ascherio A, Rimm E, Colditz G, Spiegelman D, Jenkins D, Stampfer M, Wing A \& Willett W (1997a) Dietary fiber, glycemic load, and risk of NIDDM in men. Diabetes Care 20, 545-550.

Salmeron J, Manson JE, Stampfer MJ, Coldtiz GA, Wing AL \& Willet WC (1997b) Dietary fiber, glycemic load, and risk of non-insulin-dependent diabetes mellitus in women. Journal of the American Medical Association 277, 472-477.

Selhub J, Jacques P, Bostom A, D'Agostino R, Wilson P, Belanger A, O'Leary D, Wolf P, Schaefer E \& Rosenberg I (1995) Association between plasma homocysteine concentrations and extracranial carotid-artery disease. New England Journal of Medicine 332, 286-291.

Slavin J, Jacobs D \& Marquart L (1997) Whole-grain consumption and chronic disease: protective mechanisms. Nutrition and Cancer 27, 14-21.

Stampfer M, Hennekens C, Manson J, Colditz G, Rosner B \& Willett W (1993) Vitamin E consumption and the risk of coronary disease in women. New England Journal of Medicine 328, 1444-1449.

Stampfer M \& Malinow M (1995) Can lowering homocysteine levels reduce cardiovascular disease? New England Journal of Medicine 332, 328-329.

Subbiah M (1998) Mechanisms of the cardioprotection of estrogens. Experimental Biology and Medicine 217, 23-52.

Truswell A (2002) Cereal grains and coronary heart disease. European Journal of Clinical Nutrition 56, 1-14.

Vinik AI \& Jenkins DJA (1988) Dietary fiber in management of diabetes. Diabetes Care 11, 160-173.

Welch GN \& Loscalzo J (1998) Homocysteine and atherothrombosis. New England Journal of Medicine 338, 1042-1050.

Wilcox JN \& Blumenthal BF (1995) Thrombotic mechanism in atherosclerosis: potential impact of soy proteins. Journal of Nutrition 125, 631S-638S.

Williams JK \& Clarkson TB (1998) Dietary soy isoflavones inhibit in-vivo constrictor responses of coronary arteries to collagen-induced platelet activation. Coronary Artery Disease 9, 759-764.

Zilversmit D (1979) Atherogenesis: a postprandial phenomenon. Circulation 60, 473-485. 